\title{
ZENON BAŃKOWSKI, LEITOR DE LUHMANN?
}

\author{
Marco Antonio Loschiavo Leme de Barros ${ }^{1}$
}

\begin{abstract}
Resumo
O texto discute a influência da teoria social de Niklas Luhmann na teoria do direito de Zenon Bańkowski. O objetivo é indicar a importância do papel do esclarecimento da autorreferencialidade do discurso teórico do direito. A perspectiva sociológica observa como teorias são produtos sociais ligados a determinadas práticas e circunstâncias. A obra de Bańkowski é mobilizada por meio de uma revisão de literatura e de razões históricas para exemplificar a importância de admitir esse esclarecimento. Para tanto, diferentes conceitos são correlacionados: i) da diferença sistema-ambiente para lei-amor e ii) da racionalidade dos paradoxos para a racionalidade parabólica. Tal como na visão luhmanniana em que o sistema jurídico se diferencia do ambiente para fixar sua identidade, a parábola permite compreender a tensão entre o amor e a lei, em especial a partir da argumentação jurídica e que possibilita transcender o legalismo ao mesmo tempo em que se aceita a legalidade via uma eticidade imanente. $\mathrm{O}$ teórico polonês concordaria na caracterização de um sistema aberto e fechado, além de compartilhar que o direito convive com a dúvida a respeito das diferentes possibilidades de decisão e que permanecem disponíveis para futuras seleções. O principal exemplo é o recorrente tema da contingência em sua obra e que se desdobra como o momento da ansiedade na tomada de decisão: ainda que o direito possua o desejo de controlar a contingência da vida - eliminar o risco -, ele mesmo é algo criativamente arriscado. No final, o texto sustenta que Bańkowski possui mais semelhanças com visão sistêmica do que propriamente divergências, e indica como a teoria social de Luhmann pode ser incorporada e desenvolvida no plano teórico do direito - um produto da autodescrição do sistema jurídico -, permitindo, inclusive, conjecturar se não é o caso de um acoplamento estrutural entre teoria do direito e teoria social.
\end{abstract}

Palavras-chave: Bańkowski; Teoria dos Sistemas; Teoria do Direito; Contingência; Ansiedade

\section{Introdução}

Zenon Bańkowski, polonês, radicado na Escócia, é um teórico do direito contemporâneo difícil de ser classificado. De Imagens do Direito, em 1976, até Vivendo Plenamente a Lei, em 2001, sua obra se tornou mais complexa. De um lado, não é possível

\footnotetext{
${ }^{1}$ Doutor em Filosofia e Teoria Geral do Direito pela Faculdade de Direito da Universidade de São Paulo (2018), com apoio da bolsa FAPESP. Mestre em Direito e Desenvolvimento pela Escola de Direito de São Paulo da Fundação Getulio Vargas (2014). Bacharel em Filosofia pela Universidade de São Paulo (2012). Bacharel em Direito pela Pontifícia Universidade Católica de São Paulo (2011). É professor da Faculdade de Direito da Universidade Paulista. Brasil. E-mail: marcoloschiavo@gmail.com
} 
afirmar que se trata de um representante do positivismo jurídico já que o autor não aceita a tese da separação entre direito e moral. Ao contrário, diz que a vida moral deveria ser vista, não como uma escolha entre direito e amor, mas como uma interligação e uma tensão entre os dois (BAŃKOWSKI, 2007). O amor permite uma tensão criativa essencial para o direito, refletindo os interesses do universo social. Por outro lado, o autor não abre mão da ideia de "sistema jurídico" capaz de resolver o caos normativo da vida social, tanto que um dos aspectos centrais da sua tese é indicar como é possível admitir a legalidade, evitando os problemas do legalismo ${ }^{2}$ e negando a existência de uma "resposta correta". 3

Ainda que seu modelo admita que boas decisões jurídicas sejam aquelas justificadas a partir da racionalidade do sistema - o direito atribui sentido à vida e ao mundo - , tais decisões não são suficientes para atender o desejo de certeza esperado pelo direito, ou que haveria apenas uma resposta juridicamente correta para cada caso. Para o teórico, trata-se de compreender, na verdade, o que é viver plenamente o direito, o que inclui, por exemplo, que uma boa decisão jurídica pode ser tanto aquela que cumpre à risca a lei ou, quando necessário, seja aquela capaz de violar o sistema. Presume-se uma eticidade do direito, que só quem está acostumado a viver plenamente o direito é capaz de saber quando é o caso de violá-lo.

É preciso atenção, pois, primeiro, a violação do direito não significa rompimento e determinação externa ao direito - à luz das leituras das Escolas Realistas da segunda metade do século XX, e.g., Critical Legal Studies ou Law and Economics. Ao contrário, violar é seguir o direito em outra direção por suas próprias operações, diz "[v]iver plenamente a Lei significa viver uma vida na qual a Lei é constantemente interrogada e renovada, é violada de um modo "interno" e não meramente como uma reação a algo externo a ela" (BAŃKOWSKI, 2007, p.212). Segundo, a violação em Bańkowski só é possível diante da prática da virtude da phronesis, ou como Michelon Jr. explica "um tipo de percepção moral identificada por Bańkowski, resultado da exposição particular de uma série de experiências jurídicas, que variam desde os estudos de julgados passados, das fontes do direito, da doutrina até as experiências advindas da prática do direito" (tradução nossa, 2013, p.97).

\footnotetext{
${ }^{2}$ Os problemas do legalismo em muita medida são vinculados a aceitar e seguir cegamente as regras, ou ao formalismo, que é caracterizado como uma forma apolítica, mecânica e não responsiva de tomada de decisão. Para uma discussão do formalismo a partir da obra de Bańkowski, veja Saffie, Francisco (2013). Para a defesa do formalismo veja Schauer, Frederick (2011). Além disso, em um interessante artigo Bańkowski e Schaffer discutem o legalismo na era digital, na qual aproximam o comportamento de seguir cegamente as regras à visão do "juiz-computador" (2007).

${ }^{3}$ A tese que nos casos difíceis há sempre uma resposta "correta" a ser encontrada é atribuída a Ronald Dworkin (1999), que admite que os juízes devem observar um certo tipo de integridade moral ao decidir casos controversos.
} 
A dificuldade da classificação de Bańkowski decorre, então, da impossibilidade de simplificar e rotular suas ideias, isto porque este é um dos primeiros teóricos do direito que admite e não tenta escapar do problema da contingência. Alguns comentadores enfatizam, inclusive, que, diferente de uma série de teóricos contemporâneos que buscam delimitar os âmbitos do direito, se atentando para a produção de certeza, o teórico se preocupa em uma reflexão oposta, revelando as tensões que diluem e distorcem os limites e indicam a falta de certeza do direito. ${ }^{4}$

A contingência apresentada em sua obra é, em verdade, derivada do próprio processo de esclarecimento de sua teoria. Como é sustentado ao longo desse texto, o teórico polonês admite em suas premissas o esclarecimento da autorreferencialidade que moldou seus conceitos. O próprio direito não corresponde a uma realidade objetiva, mas a um discurso constitutivo de identidade por oposição às distintas relações sociais que pressupõe e não podem ser eliminadas da vida, daí a observação da interconexão entre amor e lei. O texto identifica esse processo como um esclarecimento sociológico da teoria e que também pode ser ecoado por meio da observação de um movimento de irritação entre teoria do direito e teoria social.

Diferente de Ronald Dworkin, Joseph Raz e Neil MacCormick - seu parceiro na Faculdade de Direito de Edimburgo - que são em alguma medida resistentes à autorreferencialidade dos seus discursos, Bańkowski admite que o direito a todo o momento convive com a dúvida, seja em razão das diferentes possibilidades de decisão que poderiam ter sido tomadas e que permanecem disponíveis para futuras decisões, ou a respeito do "outro" lado do direito, ${ }^{5}$ aquele não tematizado, que gera ruído e provoca a transcendência pelas suas próprias estruturas. Como afirma o teórico, “[é] nessa maneira de conceber o sistema que podemos compreender o sistema jurídico como contendo dentro de si sua própria negação, ou seja, envolvendo em si mesmo as rupturas com o Direito" (BAŃKOWSKI, 2007, p.231).

Acredita-se que o ineditismo do teórico é em grande parte tributário das influências teóricas que são ecoadas na sua obra, em especial em Vivendo Plenamente a Lei. É por isso que o texto discute o impacto de uma delas, ${ }^{6}$ a teoria dos sistemas sociais de Niklas Luhmann.

\footnotetext{
${ }^{4}$ Veja Bell (2004) e Michelon Jr. (2007).

${ }^{5}$ Veja Fischer-Lescano (2017).

${ }^{6}$ As influências de Bańkowski são diversas, Schaffer questiona isso indicando a diversidade que marca a Escola de Edimburgo, que o teórico integra. Afirma que "os seus membros são provavelmente inspirados em uma tradição social como Karl Marx, Adam Smith, Hannah Arendt, Niklas Luhmann ou H.L.A. Hart” (tradução nossa, 2013, p.277). Em contrapartida James MacLean (2013) discute a influência dos filósofos Alfred North Whitehead, Henri Bergson, Gilles Deleuze e Michael Polanyi para o debate da zona intermediária e de incerteza que gera ansiedade para Bańkowski. As possibilidades de interpretação sobre
} 
Para tanto, o texto recorre à revisão de literatura e também às razões históricas para aproximar esses dois autores. Sustenta-se que o contato com essa teoria renovou o campo e a descrição da teoria do direito em análise, permitindo a sua tematização por meio de uma eticidade do direito. Por eticidade é possível entender o conjunto de múltiplos valores compartilhados por aqueles que vivem o direito, inclusive para ir além do sistema e defender um mundo mais justo (lawful). Trata-se de uma eticidade imanente do direito, tal como a possibilidade de uma crítica imanente do direito. ${ }^{7}$

Do ponto de vista histórico vale sublinhar que Bańkowski foi o editor da obra de Gunther Teubner, Law as an Autopoietic System (1993), e reflexivamente isso representou uma aproximação dos pressupostos da visão sistêmica, seja admitindo a teoria dos paradoxos e da complexidade, ou das ideias de autorreferência e heterorreferência.

Diante dessas considerações, o texto apresenta um paralelo entre as distinções de sistema/ambiente para lei/amor. Argumenta-se que Bańkowski trabalha com a racionalidade dos paradoxos via a racionalidade parabólica, o que permite observar o direito a partir da diferença. Se para Luhmann o sistema jurídico se diferencia do ambiente para fixar sua identidade, a parábola permite compreender a tensão entre o amor e a lei, sobretudo a partir do processo argumentativo do direito que possibilita transcender o legalismo ao mesmo tempo em que se aceita a legalidade.

Após o esclarecimento, discute-se que subjacente à racionalidade das parábolas Bańkowski incorpora em alguma medida a ideia da autofundação do direito, bem como a teoria da complexidade pressuposta por Luhmann. Admite-se que o teórico polonês concordaria na caracterização de um sistema fechado operativamente e aberto cognitivamente, além de compartilhar que o direito a todo o momento convive com a dúvida a respeito das diferentes possibilidades que poderiam ter sido adotadas para decisão e que permanecem disponíveis para futuras seleções. O principal exemplo é o tema da contingência, que aparece com frequência na obra do teórico e se desdobra como o momento da ansiedade (anxiety) na tomada de decisão. No direito este é um sentimento que se refere à autoridade, pois nunca saberá ex ante se determinada decisão é a efetivamente correta. Ainda que o direito possua o desejo de controlar a contingência da vida - eliminar o risco -, ele mesmo é algo criativamente arriscado.

as influências são variadas, todavia o presente texto envereda para as referências mais diretas que sustentam a obra do teórico.

${ }^{7}$ Veja Amato; Barros (2018). 
Por fim, é possível notar uma extensa referência à obra sistêmica nos seus trabalhos, ${ }^{8}$ destacando-se a mobilização deste instrumental para compreender as operações de reciprocidade entre o direito comunitário e os sistemas nacionais da União Europeia, bem como a ideia de integração entre sistema e ambiente para discutir os casos do tribunal do júri e do sistema de justiça leiga (lay justice) na Escócia. No final, o texto sustenta que Bańkowski é um leitor de Luhmann, o que, de um lado, impactou de maneira inédita na sua teoria do direito, e, do outro, permite conjecturar um possível acoplamento entre teoria do direito e teoria social.

\section{Da Diferença Sistema/Ambiente para Lei/Amor}

Ao ler Vivendo Plenamente a Lei é impossível não perceber que para Bańkowski há uma tensão constitutiva do direito entre lei e amor. $\mathrm{O}$ autor supera qualquer ruptura entre a marcação do lado de dentro e de fora do direito. De um lado, o direito se mantém com suas estruturas e operações internas - "argumentando dentro da máquina". O autor segue o esquematismo de uma tradição que aposta em um modelo argumentativo do direito, capaz de produzir um padrão de racionalidade jurídica e de justificar as decisões por diferentes razões subjacentes às regras. ${ }^{9}$ Do outro, o amor gera ruído e provoca tensões ao assinalar a contingência da vida do direito - "argumentando para além da máquina". ${ }^{10}$

Em grande medida Bańkowski segue as considerações de Neil MacCormick (2008) para qual a argumentação do direito segue inicialmente um modelo dedutivo atendendo dois níveis de justificação. Diz MacCormick que ao lado da justificação "interna” da decisão, que é a própria justificação por dedução, a decisão precisa oferecer argumentos "externos" atendendo uma exigência de universalidade. A universalização não está apenas condicionada à extensão da regra geral e que casos similares foram decididos de modo igual, mas também

\footnotetext{
${ }^{8}$ Bańkowski apresentou uma crítica a ideia de autopoiese, baseada na vulgata que a teoria sistêmica é um modelo anti-humanista e reacionário, no artigo "How Does it Feel to be on Your Own?: The Person in the Sight of Autopoiesis" (1994). O texto admite que tal crítica foi resultado de uma reconstrução equivocada e devidamente respondida por John Paterson (1995) e que tal crítica não comprometeu a influência da visão sistêmica na sua obra, que é observada em trabalhos posteriores. Tal debate é reconstituído neste texto.

${ }^{9}$ É possível admitir a tradição iniciada por teóricos que caracterizavam o direito como uma estrutura lógicoformal, um dos principais expoentes é Hans Kelsen com sua teoria pura do direito e que influenciou decisivamente correntes teóricas do positivismo jurídico a partir da segunda metade do século XX.

${ }^{10}$ Interessante observar que a comparação do direito como uma máquina também está em Luhmann, resgatando a ideia da cibernética e dos trabalhos do físico Heinz von Foerster. Diz o sociólogo “(...) o sistema juridico é uma máquina histórica, uma vez que toda operação autopoiética modifica o sistema ao colocar a máquina em outra posição e, dessa maneira, criar condições iniciais modificadas para outros operações. Na terminologia de Heinz von Foerster trata-se, pois, não de uma máquina trivial, que transforma sempre, e de maneira repetitiva, inputs em outputs (isso quando não comete erros ou não está quebrada), mas de uma máquina que em cada operação põe em jogo o seu próprio estado, razão pela qual a cada operação constrói uma nova máquina” (Luhmann, 2016, p. 78).
} 
se relaciona com as consequências da decisão, que devem ser consideradas como gerais, universais, consistentes (não violação com o direito vigente) e coerentes (não contradição com os princípios).

Da mesma forma em relação à Joseph Raz (1999), Bańkowski parece não divergir quanto a caracterização das regras jurídicas com razões excludentes e da possibilidade de superação por meio das razões de segunda ordem, diz "[c]hegamos a isso por meio de uma concepção do direito como sendo composto de instituições cuja formalidade e cuja natureza excludente eram fundadas em razões substantivas aceitáveis" (2007, p.177).

Todavia, essa concepção de direito é parte da história. Bańkowski também questiona o que acontece quando decisões jurídicas não se apoiam em razões subjacentes ou não cumprem a exigência de universalidade. $\mathrm{O}$ autor lembra que regras não são totalmente impermeáveis, inclusive ao perceber que possuem um caráter subótimo ao serem fundadas em acordos incompletos. Nesse caso as considerações de MacCormick e de Raz não ajudam muito nosso autor em relação as operações não triviais do direito. É possível pensar em casos em que não existe um programa a priori - texto legal, precedente ou doutrina -, ou casos inéditos (i.e., exceções não previstas em lei) que desafiam os limites do direito e colocam em questão se é possível decidir, mesmo diante do non liquet, exigindo uma grande atenção do tomador de decisão ao particular.

A ideia de "máquina” é distorcida, “[p]oder-se-ia argumentar que, em última análise, essas máquinas se diluem em razões substantivas, ou seja, dentro das particularidades do caso" (BAŃKOWSKI, 2007, p. 177). Nem toda decisão é programável. Não se discute mais a justificativa per se da decisão, mas antes um problema inicial, sobre qual decisão (ou critério) e como aplicá-la, questões que ultrapassam previamente a programação da máquina.

É neste momento que o teórico apresenta os contrastes que marcam o direito, seja entre "universalismo" e "particularismo", "respeito por regras" e "superação das regras", "lei" e "amor", ou ainda termos que reforçam a tensão do direito como "zona intermediária", "local de ansiedade" ou "unidade diferenciada". O ineditismo de Bańkowski reside, então, em não evitar a polarização ao tomar partido para um dos lados como a solução. Segundo o autor, a relevância é compreender essa tensão como inerente ao conceito de direito, trazendo à tona uma eticidade capaz de em cada caso resolvê-la.

É possível entender esse movimento também como reflexo do próprio esclarecimento sociológico em sua obra. $\mathrm{O}$ autor admite de forma holística que o direito e suas teorias refletem práticas e circunstâncias mais complexas da vida social. Destaca-se que Bańkowski não apenas repete os percursos de teorias externas ao direito ao admitir o fato de que teorias 
não são formuladas num vácuo social, mas inova ao não negar e trabalhar com o fardo das distintas histórias e raízes de cada época e sociedade. Em outras palavras, o fardo não é um problema posto à mesa já que Bańkowski se propõe a refletir sobre um sentido "realista" da teoria do direito - daí conseguir abordar o tema da eticidade do direito.

O amor está na base desta eticidade, que surge como uma força criativa e transcendente na teoria de Vivendo Plenamente a Lei. Ao mesmo tempo em que o amor é diferenciado do direito, também é observado a sua dependência. "[N]ão se pode separar o amor do direito, como não estão mutuamente opostos, já que este último está implicado no primeiro, e como a arbitrária explosão do amor carrega em si as sementes e os vínculos da racionalidade" (BAŃKOWSKI, 2007, p.106). O amor é marcado em sua teoria como o lado da contingência, das possibilidades abertas para o direito inovar e seguir em outros caminhos.

É a partir da parábola do Bom Samaritano, ${ }^{11}$ por exemplo, que o teórico indica que o amor permite perceber que em certas circunstâncias não basta seguir cegamente a lei. Tal como na parábola, é apontado a necessidade de ajudar o próximo que não estava contemplado nos termos da lei (i.e., judeus e samaritanos). Seguir a lei, não se restringe a literalidade do texto, mas é também um ato de amor que transcende momentaneamente o direito para reafirmá-lo.

O instante do particular (ou o momento do encontro) na tomada de decisão, assume um caráter sagrado na leitura de Bańkowski. Novamente, este caráter sagrado está relacionado com sua visão holística e que desvela a própria dinâmica do direito a partir dele mesmo. Diz o teórico, "creio que são as repetitivas ações do legalismo que acabam por dar respostas que vão além da segurança das repetições e, fazendo isso, transformam seu caráter repetitivo" (2007, p.215). Toda a questão é, então, equacionada para compreender as dimensões da eticidade do direito e só é possível a partir da distinção que o constitui: entre lei/amor.

Subjacente à descrição entre lei/amor está uma ideia de autorreferencialidade e heteroreferencialidade do direito, que permite Bańkowski constituí-lo como uma "unidade diferenciada”. As bases dessa ideia já estavam enunciadas na teoria dos sistemas sociais de

\footnotetext{
${ }^{11}$ A parábola aparece no Novo Testamento em Lucas10:25-37. Brevemente, trata-se da conversa entre Jesus e certo doutor da lei, que questiona o sentido da lei: "Amarás ao Senhor, teu Deus, de todo o teu coração, e de toda a tua alma, e de todas as tuas forças, e de todo o teu entendimento e ao teu próximo como a ti mesmo". O interesse da conversa é definir quem é o "próximo". Nesta ocasião Jesus narra que no caminho de Jerusalém para Jericó, um homem foi saqueado, despojado de roupas, espancado e deixado meio morto junto à estrada. Diante desta situação tanto um sacerdote como um levita, que passavam pela estrada, evitaram o homem. Finalmente, um samaritano que passava de viagem se aproximou e ajudou o homem por misericórdia. O ponto central da conversa foi indicar ao doutor da lei que samaritanos e judeus, que historicamente se desprezavam, poderiam ser considerados como próximos e alcançar a vida eterna. Tal parábola representa uma situação de interpretação que ultrapassa a literalidade da lei.
} 
Niklas Luhmann, no caso do direito destaca-se em especial a obra o Direito da Sociedade (2016), publicada pela primeira vez em 1993.

Sem a pretensão de grosseiramente resumir essa complexa teoria que marca uma transformação no campo da história da teoria social, ${ }^{12}$ basta apenas perceber que na obra de Luhmann o direito (sistema) também é observado como uma diferença em relação à sociedade (ambiente). O direito não está fora da sociedade, mas está $n a$ sociedade e de modo funcionalmente diferenciado, diz o sociólogo "[o] sistema do direito é, para insistir nesse aspecto crucial, um subsistema do sistema da sociedade. Sendo assim, a sociedade não é simplesmente o ambiente do sistema legal. Em parte, ela é mais, à medida que inclui operações do sistema jurídico, e em parte, menos, à medida que o sistema do direito tem a ver também com o ambiente do sistema da sociedade" (LUHMANN, 2016, p.74).

Direito e sociedade não se confundem, mas se pressupõem, na medida em que não é possível observar o direito sem o outro lado, que ele mesmo compõe. Aliás, para Luhmann, toda observação é uma forma de diferenciar dois lados, - a partir de dois pressupostos principais. Primeiro, a sociedade é formada pela comunicação e o direito, por sua vez, passa a ser observado como uma comunicação especializada. Segundo, o direito precisa supor a existência da sociedade. Em termos sistêmicos isto é explicado por meio do conceito de autopoiese que possibilita a diferenciação do direito em relação a sociedade. O direito produz e reproduz os seus próprios elementos que o constituem a partir de um fechamento operacional - direito é autorreferente (direito é direito), ainda que esteja pressuposto $n a$ sociedade.

No entanto, essa observação estará incompleta se não apontar também que direito e sociedade devem ser capazes de se inter-relacionar, a observação recai na heterorreferência do direito. O sistema jurídico não se encontra em um isolamento solipsista, Luhmann não nega a sociedade em relação ao direito já que gera ruído de um pelo outro. O direito consegue, portanto, se abrir para a sociedade (e vice-versa), sem prejuízo para as suas operações internas.

Basta pensar, por exemplo, que as operações do sistema jurídico em muitos casos não se limitam apenas ao direito, diz "[à] medida que o sistema do direito se utiliza da linguagem para comunicar, ele está sempre a comunicar possibilidades de associação fora do sistema jurídico" (LUHMANN, 2016, p.75). Tais possibilidades, muitas vezes, não são plenamente

\footnotetext{
12 A proposta teórica de Niklas Luhmann pretendia superar uma crise da sociologia a partir da segunda metade do século XX, que oscilava entre trabalhos empíricos e a releitura de clássicos, que seriam ultrapassados e incompatíveis com a complexidade da sociedade. É neste sentido que o texto compreende a transformação operada pela teoria dos sistemas abertos e fechados na história da sociologia.
} 
controladas pelo direito, como quando um noticiário revela notícias de um crime ambiental, ou quando são exigidas forças policiais para dar cumprimento às decisões judiciais. São comunicações que ultrapassam os filtros do direito. Vale questionar: do que adiantaria um sistema jurídico funcionando, se não houvesse um corpo policial respeitado e capacitado para fazer valer o cumprimento das decisões? Do que adiantaria a veiculação das notícias criminosas, se não existisse um corpo de promotores capazes de averiguar e apresentar denúncias com indícios de autoria e de materialidade?

Existe uma relação de simultaneidade e de coevolução entre direito e sociedade, que assegura ao mesmo tempo a dinamicidade e a existência dos sistemas - e Bańkowski problematiza tal ponto em sua obra. Não pode existir o direito sem a sociedade enquanto seu ambiente, da mesma forma que não pode existir a sociedade sem o ser humano - em termos sistêmicos, para uma devida descrição da sociedade é necessário levar em conta a interpenetração dos sistemas.

É desta forma que é possível fazer um paralelo a partir da obra de Bańkowski, sugerindo que lei/amor se aproxima da forma direito/sociedade em Luhmann. O que permite igualmente observar tal como a simultaneidade entre direito/sociedade, uma eticidade como desdobramento da lei/amor.

O paralelo sugerido, em verdade, é traçado em diversas passagens de Vivendo Plenamente a Lei ao descrever o direito como uma "unidade diferenciada". Diz o teórico, "é uma relação madura na qual as pessoas estão juntas e ao mesmo tempo são elas mesmas. Nesse sentido, são capazes de juntar suas paixões e suas necessidades de estabilidade e interligá-las de alguma forma” (BAŃKOWSKI, 2007, p.244), ou ainda afirma “(...) o inferno é ser aprisionado para sempre em nós mesmos ou em outro exatamente como nós. Ironicamente, podemos perceber isso, e podemos ser influenciados pelo "outro" que está de fora, por meio do ato de imaginação criativa que vê que somos todos semelhantes e que somos um" (BAŃKOWSKI, 2007, p.266).

A visão sistêmica é valiosa para a teoria do direito do nosso autor, pois permite desenvolver um modelo em que a eticidade não está fora do direito, mas está no direito. $\mathrm{O}$ teórico polonês precisa aceitar que existe uma distinção, não excludente e simultaneamente dependente. Na leitura sistêmica, a observação primeira é a distinção sistema/ambiente, enquanto para Bańkowski é lei/amor. Tal observação é paradoxal - como discutido na sequência -, para identificar o que é direito, pressupõe também aquilo que não é direito, logo a unidade depende também da diferença, não é possível indicar um dos lados sem indicar o outro. 
Ao interiorizar e compreender essa diferença, é possível afirmar que existe uma eticidade imanente do direito - resultado da operação dos seus próprios elementos. É por isso, por exemplo, que não é surpreendente que tanto Luhmann como Bańkowski concordariam que é a argumentação o local da criatividade, que confere validade a novos direitos e obrigações. A argumentação jurídica possibilita ao mesmo tempo a produção de redundância, operando dentro da máquina, mas também de variação ao se deixar irritar por informações da sociedade, operando para além da máquina.

Reitera-se, a eticidade aparece em Bańkowski como um "meta-critério" que domina as operações do sistema jurídico - uma observação do direito sobre ele mesmo - e que permite ao próprio direito, no momento de tomada de decisão, definir sua sensibilidade às especificidades do caso. Como isto acontece? É por meio da argumentação jurídica que ajustes são produzidos no interior do sistema, tal como uma memória que vai se transformando ao longo do tempo, ao passo em que o direito se torna um sistema de tomada de decisão cada vez mais complexo.

Na sequência avançamos no tema da argumentação jurídica para compreender o tipo de raciocínio que Bańkowski recorre para lidar com as tensões do direito. Na ocasião, um novo ponto de contato com a teoria dos sistemas é destacado, a saber: a teoria dos paradoxos.

\section{Teoria dos Paradoxos e a Racionalidade Parabólica}

O uso da parábola do Bom Samaritano não foi uma escolha aleatória para Bańkowski, para além do conteúdo, o interesse para o teórico era justamente a sua estrutura. Aliás, em Vivendo Plenamente a Lei, uma série de outras parábolas, bem como a tragédia grega, são mobilizadas para discutir as operações do direito. Uma parábola, vale lembrar, é um gênero literário metafórico que apresenta indiretamente uma lição subjacente à história. É justamente essa característica que permite ao teórico afirmar que essa narrativa curta possui um potencial para transcender o direito, indicando novas situações de aplicações da lei diante do particular. Há sempre nas parábolas o uso das figuras de linguagem, que transformam e complexificam os possíveis significados extraídos do texto.

Bańkowski indica que a argumentação jurídica se aproxima de um raciocínio parabólico, quando em alguns casos concretos, exige-se que o tomador de decisão seja criativo e reflita sobre as possibilidades de decidir a partir da narrativa altamente figurada. ${ }^{13}$

\footnotetext{
${ }^{13}$ Schafer questiona qual é a apropriada forma lógica que dê conta do raciocínio parabólico. Diz o pesquisador que “(...) é preciso trabalhar com outras formas lógicas, diferentes da lógica clássica, ferramentas que não são apenas capazes de lidar com a contradição, mas que permitem que a contradição e a tensão nos desafiem e se tornem forças criativas" (tradução nossa, 2013, p.294). Schafer sugere a
} 
É nesse sentido que diz “[a]s parábolas existem para produzir algo nas cabeças e mentes dos ouvintes, prepará-los para uma jornada transformada pelas suas ações” (2007, p.199).

As parábolas não se equivalem no direito ao raciocínio analógico, este repete padrões por meio de comparações. As parábolas recorrem as comparações, mas para produzir algo novo, uma situação que não segue padrões. As parábolas possuem dois traços importantes para Bańkowski. Primeiro, elas pressupõem que durante a tomada de decisão, a autoridade siga as regras da argumentação jurídica e observe as operações e estruturas. Segundo, o resultado desta argumentação é algo novo, que transcende as próprias operações. A parábola exige, portanto, observar a particularidade e verificar a diferenças em relação ao padrão para superá-lo.

Retomando o caso do Bom Samaritano, para esclarecer, diz o teórico, “Jesus veio não para destruir a Lei, mas para cumpri-la - mas o Direito é testado nas demandas do encontro com o particular que é capaz de transformá-lo. A Lex Talionis, por exemplo, se transforma pelo encontro com o inimigo" (BAŃKOWSKI, 2007, p.200). A parábola permite refletir sobre os limites do direito, de forma criativa. Parece que o teórico resgata o movimento direito e literatura (Law \& Literature) para apontar a existência de uma literatura própria do direito. Trata-se, efetivamente, de uma observação de segunda ordem.

Não é o caso de compreender o que a literatura pode ensinar ao direito, como no "direito na literatura". Nem é o caso de concordar com a aproximação do "direito como literatura" (ou "literatura no direito"), corrente de análise que defende a aplicação de métodos de interpretação elaborados pela crítica literária como no famoso "romance em cadeia" de Dworkin. O ponto é outro, trata-se de identificar a pluralidade de formas de um direito reflexivo, atento às exigências da sociedade - a "literatura do direito". É perceber a existência de uma racionalidade jurídica, por vezes similar ao campo da parábola.

Obviamente Bańkowski não traça linhas tão rigorosas entre direito e literatura ou trabalha com técnicas interpretativas específicas, o interesse é apenas verificar a existência de um outro lado do direito. Uma forma particular, dependente das vivências (ou de programas sociais e políticos) tal como retratados nas parábolas. Trata-se de um processo de aprendizagem do direito e que reflete nas suas operações. ${ }^{14}$

Um exemplo concreto é capaz de esclarecer o ponto do raciocínio parabólico do direito. No caso das biografias não autorizadas (ADI 4.815), a Associação Nacional dos Editores de Livros requereu a interpretação conforme à Constituição Federal (CF) dos artigos

aplicação de quantificadores trabalhados no modelo de Stanislaw Lasniewski, bem como do modelo de lógica paraconsistente.

${ }^{14}$ Para uma aproximação do ponto, veja Rocha; Oliveira (2018). 
20 e 21 do Código Civil para que fosse afastado a necessidade de autorização prévia do biografado, com base nos art. $5^{\circ}$, IX e X, da CF. Em 2015, o plenário do Supremo Tribunal Federal (STF) decidiu, por unanimidade, que "[é] inexigível o consentimento de pessoa biografada relativamente a obras biográficas literárias ou audiovisuais, sendo por igual desnecessária a autorização de pessoas retratadas como coadjuvantes ou de familiares, em caso de pessoas falecidas ou ausentes" (STF. Plenário. ADI 4815/DF, Rel. Min. Cármen Lúcia, julgado em 10/6/2015).

É possível observar o raciocínio parabólico em questão, pois a corte foi obrigada a transcender a literalidade da interpretação do Código Civil e inovar no ordenamento ao estabelecer uma exceção à regra não prevista. O plenário entendeu que a autorização prévia no caso das biografias serviria de censura, não sendo compatível com a liberdade de atividade artística e intelectual protegida pelo texto constitucional. Ao mesmo tempo o STF não seguiu o padrão de julgados anteriores, como a Lei de Imprensa (ADPF 130) ou a Lei Eleitoral de Humor (ADI 4.451), que foram fundamentados exclusivamente na liberdade de imprensa. No caso das biografias não autorizadas, a corte também ponderou que se o indivíduo biografado entendesse serem seus direitos violados pela publicação, este teria direito à indenização e outras reparações, ainda que a liberdade de expressão fosse consagrada. Tal decisão foi inédita, gerando um novo direito e obrigação diante da particularidade do caso.

A leitura parabólica de Bańkowski sobre o direito, ou mesmo o julgado do STF das biografias não autorizadas, possibilita observar uma operação paradoxal do sistema jurídico, ${ }^{15}$ isto porque o direito acaba sendo uma forma de dois lados. De um lado, observase o padrão e o arcabouço das decisões que marcam a memória e a operação regular do direito; e, de outro, a abertura para uma decisão inédita e capaz de produzir nova memória.

Tal perspectiva também ecoa à visão sistêmica que admite ser a identidade do direito formada pela diferença, ou quando sustenta que o sistema deve diferenciar-se do ambiente ao mesmo tempo em que o ambiente é produto dele. É por isso que observar o direito, é também observar a sociedade (ambiente), ou observar a lei, é igualmente observar o amor. ${ }^{16}$ Luhmann

\footnotetext{
${ }^{15}$ Bańkowski no texto "How Does it Feel to be on Your Own?: The Person in the Sight of Autopoiesis" (1994), apesar da crítica que faz ao conceito de autopoiesis, evidencia a sua ligação com a teoria dos paradoxos (p. 260-261).

${ }^{16}$ A leitura de Bańkowski relacionada ao amor também pode ser aproximada da visão de Andreas FischerLescano, quando discute o outro lado do direito a partir do debate das forças do direito. Diz o teórico alemão "é necessário reconhecer a força ou instinto de justiça como a força normativa do direito na contingência e concebê-la como pressuposto da força do direito. Somente um direito que se compreende como unidade da diferença entre força e validade jurídica e como pressuposto constitutivo de si mesmo pode aprimorar um sendo adequado para perceber as forças humanas e sócias" (2017, p. 22). O interesse para Fischer-Lescano é tornar o direito mais sensível para as situações em que o direito se transforma em violência - o que inegavelmente admite um parâmetro ético do direito em relação as suas operações.
} 
recorre à teoria dos paradoxos para dar conta de explicar essas distinções que marcam a sociedade.

Ao utilizar os paradoxos, a visão sistêmica evita a polarização e ao mesmo tempo admite a necessidade de produzir observações de segunda ordem, que permite verificar como a observação do observador acontece. É importante sublinhar que para Luhmann, seguindo a linha do construtivismo radical, a realidade é a construção da experiência do observador e que, portanto, todo conhecimento possível é também conhecimento sobre o observador esclarecimento da autorreferência do discurso.

Nesse sentido, por exemplo, para compreender a unidade do direito é necessário produzir observações de segunda ordem sobre o sistema jurídico, capaz de descrever como o sistema auto-observa. Igualmente, sugere-se que ao afirmar a existência de uma eticidade do direito, Bańkowski também apresenta, pelo direito, uma observação de segunda ordem. É dizer, como o direito se observa, em especial no plano da argumentação.

A argumentação sempre vê a si mesma em uma situação de observação de segunda ordem, reflete as próprias possibilidades de aplicação e justificação do texto legal à luz do caso concreto, inclusive permitindo refletir outras possibilidades que ali não estão cristalizadas. Veja Luhmann, "[e]sses textos normativos possibilitariam ao sistema reagir às irritações pertinentes, sem a necessidade de ter pleno controle de suas operações" (2016, p.541).

Bańkowski detalha mais o momento da argumentação do que a visão sistêmica. $\mathrm{O}$ teórico caracteriza o momento de decidir e apresentar as razões da decisão como um local que gera ansiedade (anxiety), indicando que a atividade de decisão é algo arriscado e paradoxal, diz "[1]á eu tenho de tomar decisões que me expõem, e não posso me obrigar na segurança que é gerada pela certeza (...) mesmo que solução seja óbvia, é impossível ter certeza de que tudo dará certo no final das contas, saber de antemão exatamente para onde as coisas irão se encaminhar" (2007, p. 189). A ansiedade é tomada como um sentimento da autoridade e que marca o processo de tomada de decisão ao colocar em evidência a responsabilidade (moral) pela decisão, que é feita no instante particular.

A ansiedade também pode ser compreendida por uma dimensão temporal da decisão, que evidencia novamente o caráter paradoxal. Tudo o que o direito produz são operações presentes a partir de programas condicionados, decisões são determinadas em relação aos eventos passados. ${ }^{17}$ Mesmo que se questione, ou se exige, uma operação em relação ao futuro,

\footnotetext{
${ }^{17}$ Bańkowski trabalha isso metaforicamente recorrendo a ideia de jornada, “(...) minha tese é que o futuro é vivido no presente, por meio dos ideais que tornaram essa conexão entre futuro e presente possível. Nesse sentido, pode-se dizer que a abertura e a indeterminação do fim da jornada são preservadas, mas ao mesmo
} 
o direito apenas consegue produzir uma solução presente, grosseiramente antecipando uma situação altamente incerta.

Tal situação explicaria, portanto, porque o direito possui dificuldades regulatórias em promover determinadas pretensões na sociedade, ou mesmo, retomando a questão da responsabilidade (moral), porque o juiz pode estar correto juridicamente ao sentenciar alguém à morte e ainda sim ser contra a pena de morte. Essa dificuldade é também colocada de modo paradoxal em relação ao futuro, pois nenhum juiz saberá de antemão como se comportará diante do caso particular (i.e., futuro contingente).

Na leitura de Bańkowski a questão não é saber se o juiz vai sentenciar alguém à morte, mas compreender que no caso deste réu, diante destas circunstâncias, esta decisão envolve razões morais que podem ser tão fortes a ponto de tanto justificar o cumprimento da regra, ou de superar a regra por não acreditar na correção oferecida diante da particularidade. A questão é saber, portanto, como o juiz se comporta diante do particular, que sempre coloca em questão a tensão do direito.

Se retomar o caso das biografias não autorizadas, é possível indicar que os julgados anteriores ao caso em nada contribuíam para o problema dos indivíduos biografados que não autorizavam que suas histórias fossem contadas. Como memória, essas decisões reforçavam uma leitura sobre a liberdade de imprensa, que não era similar ao problema enfrentado e o direito brasileiro estava acostumado à compreensão que tal situação não poderia ser considerada como censura diante da exigência estabelecida pelos artigos 20 e 21 do Código Civil, que restringiam à publicação de pessoa biografada. Percebe-se, assim, que o direito em certa medida não enfrentava a particularidade do caso.

Foi no plano argumentativo que surgiu a possibilidade de ultrapassar essa compreensão, quando outros programas do direito são mobilizados para ponderar essa tensão, de um lado proteger a liberdade de manifestação de pensamento vis-à-vis o direito à intimidade. A responsabilidade pode ser compreendida na percepção que os ministros tinham que a correção oferecida pelo Código Civil não se ajustava neste caso das editoras e diante destas circunstâncias. Não é à toa que o STF aplica os ditames constitucionais para indicar que a liberdade das editoras é constitucionalmente assegurada, não se podendo anular por outra norma constitucional com base no inc. IV do art. 60, ou por lei infraconstitucional, ainda que sob o argumento de proteger outro dispositivo constitucional que assegura o direito

tempo estão entrelaçados aos ideais, que estão lá para impedir que nossa jornada saia completamente do curso" (2007, p.238). 
à intimidade, à privacidade, à honra e à imagem. A solução resolve a tensão particular sem reduzir e limitar plenamente os direitos, cria uma nova situação.

A corte defendeu a coexistência, conjugando-se o direito às liberdades com a inviolabilidade da intimidade, da privacidade, da honra e da imagem da pessoa biografada e daqueles que pretendem elaborar as biografias, ambos protegidos constitucionalmente. Interessante é observar que a decisão do STF pode ser vista como uma atividade arriscada, pois havia uma expectativa para que a corte defendesse um dos direitos em prejuízo do outro.

Nos discursos de época do julgamento isto era facilmente observado pela classe artística. Os principais argumentos contra o pleito dos editores estavam relacionados ao interesse do mercado editorial e à proteção ao direito à privacidade dos artistas de maneira absoluta. Todavia, a visão moral da corte era outra, pois nenhum juiz aceitou a liberdade de manifestação do pensamento, e consistentemente afirmou que era favorável a uma censura do tipo previsto no Código Civil, quando envolvesse a atividade artística e intelectual. As razões morais predominaram no sentido de justificar pelo direito a solução de coexistência já delimitada pelo texto constitucional para o caso das editoras.

Todavia, veja que esta solução não é necessariamente a compreensão de toda a sociedade brasileira. Mesmo após a decisão, alguns argumentam ainda que a falta de um marco legal que indique a real liberdade de expressão nas obras prejudica a publicação das biografias não autorizadas uma vez que a censura prévia combatida pelo STF se transformou, na prática, em autocensura prévia controlada pelas editoras. ${ }^{18}$ Este caso ilustra bem como as consequências da decisão escapam do controle do direito e, inclusive, reforçam uma posição (moral) contrária aquela defendida pela corte.

Diante dessas considerações, é possível perceber que a teoria de Bańkowski apresenta uma leitura transformadora sobre o papel do direito na sociedade - ponto que já se distancia da visão sistêmica, enquanto uma sociologia jurídica sem pretensões normativas explícitas. Viver plenamente o direito é uma forma de transformar e continuar a jornada pelo direito, que, por vezes, é um caminho que possibilita a emancipação, justiça e que é também completamente contingente. ${ }^{19}$

\footnotetext{
${ }^{18}$ Veja "Um ano após a liberação das biografias, decisão não abriu a porteira para as não autorizadas", 2016. Disponível em < http://cultura.estadao.com.br/noticias/literatura,um-ano-apos-a-liberacao-dasbiografias-decisao-nao-abriu-a-porteira-para-as-nao-autorizadas, $10000055171>$. Acesso em 04 de jun. de 2017.

${ }^{19}$ Destaca-se que essa leitura em grande medida é um giro teórico que ecoa na própria trajetória do autor, quando afirma "meu objetivo é repensar e reconstruir o anarquismo que subjaz aos meus trabalhos anteriores como, por exemplo, Images of Law. Faço isso para que se possa perceber como a autonomia moral, que é tão valorizada pelo anarquismo, pode ser encontrada, não na rejeição do Direito, mas, ao invés disto, na sua compreensão; na compreensão daquilo que a legalidade realmente significa" (BAŃKOWSKI,
} 
Diferente de outros teóricos que rejeitam qualquer papel emancipatório do direito, por justamente ser instrumento de controle e manutenção de desigualdades - estruturas condicionadas pela base material da sociedade -, nesta outra chave, o direito pode romper com a ordem e apontar para um novo caminho, quando produz uma reflexão do paradoxo. Como já mencionado, o rompimento não é completo, pois Bańkowski pressupõe o direito, e, além disso, o novo caminho é apresentado no instante do particular, portanto muito resultados produzidos são pontuais e às vezes as consequências não podem ser juridicamente controladas. A transformação é um processo de aprendizado por meio da atuação pontual de diferentes organizações, bem como limitado pelas operações do sistema.

Na sequência, dois casos concretos são discutidos, para, novamente, aproximar o teórico polonês com a teoria social de Luhmann. Os casos podem ser considerados como situações limites, que exigem compreender o caráter paradoxal do direito. Para o texto o interesse é perceber que tal aproximação se torna cada vez mais evidente. Bańkowski se refere expressamente à teoria social sistêmica como uma forma de observação da sociedade. No entanto, algumas ressalvas são indicadas na medida em que o autor apresenta uma crítica infundada à ideia de autopoiese.

\section{A Autopoiese é um Problema para Bańkowski?}

Uma das preocupações de Bańkowski é justamente indicar que o direito não é um sistema solipsista. O autor indica uma série de estruturas e organizações que asseguram a abertura do direito. Tal como visto anteriormente, uma forma de observar a abertura é por meio da argumentação, que abre a possibilidade de inovação pelo intérprete e por meio da lei. No entanto, o autor também discute como essa abertura ocorre no plano das organizações. Trata-se de observar o que ele chama de "instituições ponte", organizações que estão simultaneamente dentro e fora do direito e que possibilitam que o "lado de fora" seja filtrado pelo direito (BAŃKOWSKI, 2007, p.206-207).

$\mathrm{Na}$ chave sistêmica as "instituições ponte" nada mais são que as observações de correspondência ponto por ponto entre sistema e ambiente. Dois são os principais exemplos para Bańkowski, o tribunal do júri e a justiça leiga. Em ambos os casos as autoridades decisórias não são formadas em direito e, portanto, estão situadas simultaneamente na sociedade e no direito. Diz o teórico, “[j]á que essas instituições "ponte” têm um pé em cada mundo, a máquina do Direito pode ser subvertida, porque a observação das particularidades

2007, p.xxvii). Para uma compreensão detalhada da mudança de posição na sua trajetória teórica, veja Bańkowski (2002). 
de um caso pode também ser compreendida como um ato juridicamente relevante" (2007, p.208).

Em Luhmann essa leitura é evidente quando discute a situação dos tribunais no sistema jurídico, que estão situados no centro e exigem um autoisolamento cognitivo de intensidade maior em relação à periferia (2016, p.397-450). A distinção centro/periferia é de grau porque diferentes procedimentos jurídicos podem assegurar a abertura cognitiva dos tribunais, como amicus curiae, a avaliação e importância da opinião pública no processo judicial e os próprios mecanismos de ações coletivas ou de incorporação de argumentos extrajurídicos. Aliás, na visão sistêmica, as organizações não precisam observar as fronteiras dos sistemas funcionais, pois os únicos limites que são observados nestes casos são os organizacionais. Tribunais podem estar operando tanto no direito, como na economia e na política, basta pensar na atuação de uma corte constitucional, que deve desenvolver uma sensibilidade para às demandas e os acontecimentos da sociedade.

A ideia de organizações mais sensíveis pela visão sistêmica está diretamente evidenciada em Bańkowski quando discute que teoria dos sistemas possibilita observar a produção de ruídos que modificam o encaminhamento do direito por essas "instituições ponte". Diz o teórico, "esses elementos leigos apontarão o caminho e de fato darão a respostas recalculando todas as opções e revisando seus parâmetros" (2007, p.225).

O texto acredita, na verdade, que tal ideia não está apenas vinculada às "instituições ponte", mas à situação de observação já que toda e qualquer organização pode observar a sociedade a partir de diferentes posições. Desta forma, conforme as estruturas de abertura e a sensibilidade, diferentes tipos de comunicação que existem no ambiente podem ser filtrados, sobrepostos e traduzidos como uma distinção interna que é controlada no nível organizacional. ${ }^{20}$

Um outro exemplo que Bańkowski discute em Vivendo Plenamente a Lei a partir da teoria dos sistemas é a relação entre o direito comunitário e os direitos nacionais da União Europeia. O autor questiona: como entender, por exemplo, a decisão do Tribunal de Justiça da União Europeia que estabeleceu que as disposições do Merchant Shipping Act e sua

\footnotetext{
${ }^{20}$ No texto "Organizações e Decisões" de 1978 Luhmann já sustentava que organizações são sistemas autopoiéticos de decisão (e não sistemas de função), e a cada operação se tornam cada vez mais complexos. Organizações unem novas decisões com decisões passadas ao mesmo tempo que em que desenvolvem e controlam a capacidade de inovar, "a capacidade de inovação é ao mesmo tempo, na maioria dos sistemas organizacionais, uma variável crítica e valorada como tal" (tradução nossa, 2005, p. 95). Interessante é perceber que os sucessos das organizações também dependem de uma "consciência" sobre as alternativas decisórias possíveis. Sustenta que as organizações fixam seu ambiente, que não necessariamente se limitam aos dos sistemas, mas do campo das suas decisões, diz "suas restrições sistêmicas internas derivam consideravelmente da situação que seu ambiente se encontra organizado e somente acessível em relação às decisões" (tradução nossa, 2005, p.61).
} 
regulamentação feitas pelo governo do Reino Unido, então membro da Comunidade Europeia, eram incompatíveis com o direito comunitário, em especial com o freedom of establishment? Haveria um problema de jurisdição por incompetência territorial? Uma afronta à soberania do Reino Unido?

O interesse é entender como funcionam as relações de reciprocidade entre os distintos níveis do direito, em especial saber como as decisões dos tribunais nacionais estavam submetidas à jurisdição comunitária. Para tanto, o autor recorre à ideia autopoiética, diz “(...) temos um exemplo de uma conexão autopoiética, pois pode-se dizer que o tribunal nacional, ao aplicar o Direito nesse caso, age ao mesmo tempo como parte do sistema comunitário europeu e como uma parte do sistema nacional. Por meio de um unum actum conecta os dois sistemas.” (BAŃKOWSKI, 2007, p. 224).

Novamente, vale lembrar que na visão sistêmica a observação dos tribunais no sistema do direito ocorre por meio da forma centro/periferia. Porém, há outras diferenciações em relação ao centro, a saber: superioridade/inferioridade. Diz Luhmann, "[s]omente os tribunais constituem uma hierarquia, somente eles se diferenciam horizontalmente segundo as distintas competências espaciais ou profissionais" (2016, p.432). Assim, por exemplo, o Tribunal de Justiça da União Europeia é observado tanto como uma corte do direito comunitário, quanto como uma corte de todos os sistemas nacionais. A distinção ocorre apenas em relação ao centro - i.e., em relação aos demais tribunais -, mas não em relação ao direito.

Uma leitura atenta até este ponto pode sugerir que Bańkowski não diverge da teoria dos sistemas. Aceita plenamente a teoria dos paradoxos, da complexidade e da ideia de autofundação dos sistemas. Todavia, sua aceitação encontra ressalvas. No texto "How Does it Feel to be on Your Own?: The Person in the Sight of Autopoiesis" (1994), o teórico apresenta uma forte desavença em relação ao conceito de autopoiese e, por sua vez, ao pressuposto do construtivismo radical trabalhado pela teoria dos sistemas.

O texto acredita que tal desavença, na verdade, foi diminuta e equivocada, na medida em que o teórico se baseou em uma vulgata que identifica a teoria sistêmica a um modelo anti-humanista e reacionário. A crítica do autor pode ser assim sintetizada, a ideia de autopoiesis encerra na teoria dos sistemas uma separação radical entre os sistemas. Os sistemas cada vez mais estão isolados uns dos outros por meio de suas operações. Subjacente a essa descrição encontra-se a crítica que o isolamento é reflexo da eliminação do ser humano e da categoria de ação das observações oferecidas pela teoria dos sistemas, diz "[para teoria dos sistemas] sentido social é produzido pelos elementos do sistema sem referência ao 
sistema psíquico. Portanto, se seres humanos não existem no sistema social, mesmo assim o sentido social ainda estará assegurado na visão sistêmica. O mundo ainda produzirá sentido sem a presença de vida humana" (tradução nossa, BAŃKOWSKI, 1994, p.259).

O problema desta reconstrução está no fato de Bańkowski ignorar que para Luhmann "a sociedade tem de ser vista como um ambiente social que possibilita essa autoprodução do direito [e dos demais subsistemas] e que, tanto mais, dá sustentação ao direito produzido" (LUHMANN, 2016, p. 40). Desta forma, por exemplo, o ser humano não é eliminado, mas apresentado como ambiente da sociedade.

Segundo John Peterson, em resposta formulada no artigo "Who is Zenon Bańkowski Talking to? The Person in the Sight of Autopoiesis" (1995), o teórico polonês acaba adotando essa vulgata por justamente se limitar aos trabalhos sistêmicos sobre o direito via Gunther Teubner, e não observar demais obras que discutem o sistema social e a teoria social.

Existiria um missing Hamelet no pensamento do autor já que desconsidera a teoria de Luhmann, diz "[s]into que, no caso do artigo de Bańkowski, o Hamlet faltante é decisivo. O que Luhmann disse sobre a inter-relação é muito importante já que esclarece a relação entre os sistemas de sentido, psíquico e social, o que tem um enorme impacto sobre a visão de Bankowski sobre o indivíduo em relação à autopoiese" (tradução nossa, PETERSON, 1995, p. 214).

O texto concorda com Peterson, apontando que Bańkowski ignora que Luhmann admite a coevolução e simultaneidade entre os sistemas de sentido (psíquico e social). Ora, não é possível observar o sistema da sociedade sem o ser humano enquanto ambiente, da mesma forma que não é possível observar o direito fora da sociedade.

Isto confirma, seguindo pressupostos do construtivismo, que se a teoria sustenta que nunca podemos ter acesso direto à realidade, também não pensa que a realidade não existe "lá fora". Peterson ainda avança indicando que a dificuldade que a autopoiesis coloca para a teoria do direito é que já estamos completamente socializados, somos socializados todo o caminho, mesmo por linguagem e sentido, e não há escapatória (1995, p.227).

Em que pese o nosso autor reconstituir uma parte da teoria dos sistemas de maneira incompleta, o texto acredita que ambos os modelos compartilham vários pontos de contato. O central é que tanto Bańkowski como Luhmann não sustentam que o direito é um sistema solipsista. Ambos concordam com a observação da complexidade de sistemas que são fechados porque abertos (e vice-versa), ou que lei/amor caracteriza a tensão central do direito.

Além disso, é interessante observar que essa socialização que se refere Peterson também incide no plano teórico - o que reforça a importância da atenção à 
autorreferencialidade do discurso. Revela-se, portanto, a importância da conexão entre teoria do direito e teoria social. ${ }^{21}$ Como apresentado ao longo deste texto, acredita-se que Bańkowski admite a teoria social em seu modelo. Enquanto leitor de Luhmann - apesar da vulgata -, o teórico consegue vislumbrar um acoplamento no nível teórico. Tais considerações são apresentadas na sequência como parte final.

\section{Considerações Finais}

Se, de um lado, Bańkowski é leitor de Luhmann, e, como sublinhado neste texto, isto é decisivo na sua teoria para indicar como opera a eticidade imanente do direito a partir da forma parabólica. Do outro, em relação à teoria dos sistemas, é possível conjecturar se o modelo do teórico polonês não é um caso de acoplamento entre teoria do direito e teoria social. A pergunta é interessante, pois exige refletir como a teoria do direito opera na sua base.

Primeiro, é preciso lembrar que a teoria do direito é uma autodescrição do sistema e que em muitos casos se tornam teorias reflexivas sobre como o direito opera. Entretanto, por ser produto da auto-observação do sistema, por estar situado internamente ao sistema, essas teorias não conseguem descrever a unidade, o sentido e função do direito. ${ }^{22}$

Segundo, Luhmann não descarta a possibilidade de conexão entre teoria do direito e teoria social, diz "[s]ob a rubrica teoria do direito, é possível efetivamente propor uma integração de ambas as perspectivas, mas a partir da teoria dos sistemas é preciso contar com abordagens que tornem a separar uma da outra, tão logo deem conta do que é especificamente requerido por uma teoria" (2016, p.32). Para Luhmann, portanto, a teoria precisa observar seu objeto como observador e esta é a principal exigência para a conexão teórica. Vale pontuar, ambas precisam se observar e gerar mutuamente ruídos.

\footnotetext{
${ }^{21}$ Peterson afirma criticando o teórico polonês "[o] véu de ignorância exigido para lidar com o tipo de preocupações que a Bańkowski tem em mente envolveria não apenas a remoção de certos atributos, mas a remoção de todos os atributos sociais, até o bloqueio das sinapses, se eles potencialmente trazem significado" (tradução nossa, 1995, p.227). Diferente de Peterson neste ponto, o texto acredita que Bańkowski evita o véu por justamente incorporar, ainda que implicitamente, os pressupostos da teoria dos sistemas em seus trabalhos. A sua crítica em relação ao conceito de autopoiesis em nada prejudicaria esta incorporação, pois, ao longo deste texto ficou esclarecido como o teórico também trabalha a racionalidade paradoxal e a autofundação dos sistemas, incluindo aí o par de observação autoreferrência/heteroreferrência.

${ }^{22}$ Diz Luhmann que somente no campo da sociologia jurídica, inserido no sistema científico, seria possível compreender as distinções constitutivas do direito, "[a]o contrário das teorias jurisprudenciais, da filosofia do direito ou de outras teorias do direito, que têm como objetivo o próprio uso no sistema jurídico ou que queiram apreender e assimilar o que faz sentido no sistema jurídico, a sociologia do direito dirige-se à ciência e não ao sistema jurídico" (2016, p. 41).
} 
A teoria dos sistemas procura descrever como o sistema produz seus próprios limites em relação ao ambiente, e no caso do direito, também descreve sua auto-observação, incluindo aí a teoria do direito. No caso da teoria do direito de Bańkowski, também é possível identificá-la como uma observação interna sobre como o direito refaz a todo o momento os seus limites, ganhando relevância na descrição a questão da eticidade, que remete a uma teoria social de fundo.

Como já pontuado, a eticidade opera como uma observação de segunda ordem, que reflete as operações do direito e possibilita introduzir as mudanças observadas da sociedade no plano teórico. E o ponto de contato está nos diferentes exemplos que estes teóricos recorrem para indicar a unidade diferenciada do direito, desde do nível argumentativo até organizacional.

Terceiro, considerando a abertura cognitiva que a eticidade possibilita ao sistema jurídico, em especial considerando as descrições sistêmicas, é possível sugerir que no nível teórico ambos os modelos estariam acoplados estruturalmente.

Vale lembrar que Luhmann identifica no conceito de acoplamento estrutural a possibilidade de descrever como o direito se relaciona com outros sistemas (ambiente para o direito). O acoplamento é um canal privilegiado de irritações que o direito mantém com outros sistemas. No caso dos sistemas direito e economia, o sociólogo identifica como mecanismos de acoplamento a propriedade e o contrato. No caso dos sistemas direito e política, é a constituição quem possibilita a irritação. O interessante para este texto é observar que nos sistemas direito e ciência é a teoria do direito quem atua como instância de articulação entre esses sistemas - ponto já defendido por autores em outros contextos como De Giorgi, 2017; Nobles, Schiff, 2006; Ewald, 1988.

O texto sustenta que esse acoplamento não estaria diretamente relacionado com a argumentação jurídica ${ }^{23}$ - ou possibilitado pela forma da retórica - , mas, antes, no nível teórico (ou reflexivo) do sistema jurídico. Seria possível sugerir que as irritações seriam observadas de uma maneira reflexiva, isto porque a teoria do direito não se confunde em termos operativos com a dogmática jurídica.

É o caso, por exemplo, de seguir a leitura de Manuel Calvo Garcia (2014), mobilizando a teoria hartiana, ao indicar que uma teoria sociológica do direito depende de uma revisão da tese do "imperialismo filosófico" predominante nas teorias do direito. De

\footnotetext{
${ }^{23}$ Destaca-se que Carvalho Neto trabalha o acoplamento a partir do nível argumentativo e encontra na forma da retórica a possibilidade de operacionalmente traduzir e incorporar no sistema jurídico o conhecimento da sociedade. No entanto, difere dessa posição apontando para a incorporação primeira nas operações teóricas do direito.
} 
forma mais modesta, a revisão pode ser compreendida também por meio da observação das transformações e irritações entre a sociologia do direito e a teoria do direito - planos reflexivos dos sistemas sociais.

Vale lembrar que no início da obra Direito da Sociedade Luhmann se esforça para diferenciar e indicar que a teoria do direito foi se desvinculando de uma teoria das observações da prática e das decisões dos sistemas para se tornar ela mesma em uma teoria de observações de segunda ordem. Vale dizer uma teoria que observa o modo em que o direito se vê. ${ }^{24}$

A teoria de Bańkowski parece conduzir para essa compreensão transformadora da teoria do direito. É a partir da ideia de eticidade, por vezes transfigurada como parábola, que o direito opera com conhecimentos observados da sociedade, em especial das descrições da teoria social dos sistemas. A eticidade serve como um termostato, que mantém a temperatura do sistema a partir daquilo que a teoria social gera como irritação por meio de suas descrições. Desta forma, preserva-se a autonomia do direito, mas também é assegurada a possibilidade de identificar mudanças do ambiente em um nível reflexivo do direito.

Uma atenção final deve ser notada. As mudanças mencionadas no texto estão relacionadas ao âmbito da teoria do direito, e não propriamente da dogmática jurídica. O texto segue a tendência de abstração que Luhmann identifica nas teorias do direito a partir da segunda metade do século XX (2016, p. 15-16), apontando que essas teorias já se preocupam em descrever o modo que o direito se vê a partir de seu próprio entendimento.

No entanto, muitas dessas teorias ainda se mantêm limitadas pela ausência de irritação com a teoria social, ou contaminadas pelo "imperialismo filosófico". No início deste texto afirmou-se ser difícil classificar a obra de Bańkowski. Ora, tal dificuldade decorre da constatação que o teórico polonês não oculta os pontos cegos de sua teoria, o que justamente enrique sua reflexão ao problematizar o ponto.

É possível superar o "imperialismo filosófico" ao admitir a autorreferencialidade do discurso como um esclarecimento sociológico: teorias são produtos sociais ligados a determinadas práticas e circunstâncias, o que deve ser problematizado por qualquer teórico. $\mathrm{Na}$ história da teoria do direito a aproximação entre teoria do direito e teoria social, sobretudo

\footnotetext{
${ }^{24}$ É desta forma que Luhmann distingue os campos da dogmática jurídica, da teoria geral do direito e da filosofia do direito, diz: “(...) somos levados a reconhecer que o que existe como teoria do direito nasceu quase sempre em conexão com as autodescrições do sistema jurídico. São esforços teóricos que, apesar da disposição para a crítica, em primeiro lugar respeitam o direito e comprometem-se com as vinculações normativas equivalentes. Isso vale tanto para as teorias jurídicas no sentido estrito, que se desenvolveram a partir da prática casuística e relacionam suas regras a pontos de vista gerais, como para teorias de reflexão do sistema jurídico que representam o valor intrínseco da produção do direito e do sentido de sua autonomia" (2016, p.23).
} 
via teoria dos sistemas, pode representar uma mudança de paradigma, que atualmente ganha novos postulantes. Afinal de contas como Luhmann destacava: uma sociedade complexa reclama por uma teoria complexa.

\title{
ZENON BAŃKOWSKI, THE LUHMANN READER?
}

\begin{abstract}
The paper discusses the influence of Niklas Luhmann's social theory on Zenon Bańkowski's theory of law. For this purpose, I argue the importance of clarifying the self-referentiality from theoretical discourse of law. The sociological perspective observes how theories are social products linked to certain practices and circumstances. Bańkowski's work is mobilized through a review of literature and historical reasons to exemplify the importance of admitting this sociological clarification in its premises. In order to confirm the clarification of the theory, different concepts are correlated: i) from the system-environment difference to lawlove and ii) from the rationality of paradoxes to parabolic rationality. Just as Luhmann that the legal system differs from the environment to establish its identity, for Bańkowski the parable allows us to understand the tension of the legal reasoning between love and law. In this sense, the legal reasoning makes it possible to transcend legalism while accepting legality via an immanent ethics. The Polish author would agree on the characterization of an open and closed system, in addition to sharing that the law coexists with the doubt regarding the different possibilities of decision and that remain available for future selections. The main example is the matter of contingency, which appears frequently in his work and unfolds as the moment of anxiety in decision making: although the legal system has the desire to control the contingency of life - eliminate the risk - it is itself something creatively risky. Finally, the paper suggests that Bańkowski has more similarities rather than proper disagreements with the systemic view. I suggest that Bańkowski's work is an important case about how Luhmann's social theory can be incorporated and developed in legal theory - a product of the self-description of the legal system -, and, perhaps, being an example of a structural coupling between legal theory and social theory.
\end{abstract}

Keywords: Bańkowski; Systems Theory; Legal Theory; Contingency; Anxiety

\section{Bibliografia}

AMATO, Lucas; BARROS, Marco Antonio L. L. de (orgs.). Teoria Crítica dos Sistemas?

Crítica, teoria social e direito. Porto Alegre: Editora Fi, 2018.

BAŃKOWSKI, Zenon. Vivendo Plenamente a Lei. Rio de Janeiro: Elsevier, 2007 . "Images of 'Images of Law”. Social \& Legal Studies 11(3), 2002, p. 445-453

. Living Lawfully: Love in Law and Law in Love. Kluwer Academic Publishers, 2001

. "How Does it Feel to be on Your Own?: The Person in the Sight of Autopoiesis",

Ratio Juris, 1994

BAŃKOWSKI, Zenon; MUNGHAM, Geoff. Images of Law. Routledge and Kegan Paul, 1976 
BELL, John. The Perspective of the Ordinary citizen on Law. Res Publica, v.10, n. 2, 2004, pp. 311-317.

BRASIL. Supremo Tribunal Federal. ADI 4815/DF, Rel. Min. Cármen Lúcia, DJe de 01 de fevereiro de 2016.2 Disponível em: $<$ http://redir.stf.jus.br/paginadorpub/paginador.jsp?docTP=TP\&docI D=2243342>.

CARVALHO NETO, Pythagoras. Retórica e Consistência no Direito: Fundamentos para uma Teoria do Direito de Inspiração Luhmanniana. Curitibia: Juruá, 2016.

DE GIORGI, Rafaelle. Ciência do direito e legitimação: crítica da epistemologia jurídica alemã de Kelsen a Luhmann. Curitiba: Juruá, 2017.

DWORKIN, Ronald. O Império do Direito. São Paulo: Martins Fontes, 1999.

EWALD, François. “The Law of Law”. In: TEUBNER, Gunther. Autopoietic Law: a new approach to Law and Society. Berlin: Walter de Gruyter, 1988, p. 36-50.

FISCHER-LESCANO, Andreas. Força de Direito. Rio de Janeiro: Lumen Juris, 2017.

GARCIA, Manuel Calvo. "Positivismo Jurídico y Teoría Sociológica del Derecho". Oñati Journal of Emergent Socio-legal Studies, vol. 6, Issue 1, 2014, pp. 46-66.

LUHMANN, Niklas. O direito da sociedade. São Paulo: Martins Fontes, 2016.

Organización y decisión. Autopoiesis, acción y entendimento comunicativo.

México: Athropos, 2005.

MARIA, Julio. Um ano após a liberação das biografias, decisão não abriu a porteira para as não autorizadas, 2016. Disponível em: $<$ http://cultura.estadao.com.br/noticias/literatura,umano-apos-a-liberacao-das-biografias-decisao-nao-abriu-a-porteira-para-as-naoautorizadas,10000055171>. Acesso em: 04 de set. 2017.

MACCORMICK, Neil. Retórica e o Estado de Direito. Rio de Janeiro: Elsevier, 2008.

MACLEAN, James. "Holding the Middle, or Dancing on the Edge...?". In DEL MAR, Maksymilian; MICHELON JR., Cláudio (ed.) The Anxiety of the Jurist. Ashgate Publishing, 2013, p. 257-276

MICHELON JR., Cláudio. "But to Life Inside the Law, You Must Be Honest”. In DEL MAR, Maksymilian; MICHELON JR., Cláudio (ed.) The Anxiety of the Jurist. Ashgate Publishing, 2013, p. 83-100

. Sobre o significado de viver o direito: Uma Introdução a Vivendo Plenamente a Lei. In BAŃKOWSKI, Zenon. Vivendo Plenamente a Lei. Rio de Janeiro: Elsevier, 2007, p. v-xxi

NOBLES, Richard; SCHIFF, David. A sociology of jurisprudence. Oxford: Hart Publishing, 2006. 
PETERSON, John. "Who is Zenon Bankoski Talking to? The Person in the Sight of Autopoiesis. Ratio Juris, 1995, p. 212-229

RAZ, Joseph. Practical Reason and Norms. Oxford, 1999.

ROCHA, Leonel Severo; OLIVEIRA, Júlia Francieli Neves. "O direito como pressuposto do horizonte literário: uma nova compreensão da realidade jurídica”. Quaestio Iuris, vol. 11, $\mathrm{n}^{\circ}$. 3, Rio de Janeiro, 2018, pp. 1653-1669.

SAFFIE, Francisco. "Fulfilling the Law by Breaking It? Formalism within Legality". In DEL MAR, Maksymilian; MICHELON JR., Cláudio (ed.) The Anxiety of the Jurist. Ashgate Publishing, 2013, p. 155-172

SCHAFER, Burkhard. "A Logical Journey: The Anxiety of the Lesniewski Quantifiers". In DEL MAR, Maksymilian; MICHELON JR., Cláudio (ed.) The Anxiety of the Jurist. Ashgate Publishing, 2013, p. 277-298

SCHAFER, Burkhard; BAŃKOWSKI, Zenon "Double-click Justice: Legalism in the Computer Age”. Legisprudence Vol 1, 2007 p. 31-49

SCHAUER, Frederick. Formalismo. In: José Rodrigo Rodriguez. (Org.). A justificação do formalismo jurídico: textos em debate. 1ed.São Paulo: Saraiva, 2011, pp. 65-116

Trabalho enviado em 06 de novembro de 2018

Aceito em 24 de fevereiro de 2019 